\title{
Características morfológicas e produtividade de cultivares de alho em manejo orgânico na microrregião do Campo das Vertentes (MG)
}

\author{
Morphological characteristics and yield of garlic cultivars in organic \\ management in the micro-region of the Campo das Vertentes, MG
}

\author{
Breno José de Oliveira Terra ${ }^{1}$ \\ Julio César de Araújo ${ }^{2}$ \\ Rovilson José de Souza ${ }^{3}$
}

\section{Abstract}

The economic importance of garlic has increased considerably in recent years and is cultivated in most of Brazil, is a vegetable that stands out not only for its use as a condiment, but also for its therapeutic properties. Garlic is a vegetable that has a lot of clones with different regional names, such fact makes many alicultores acquire materials unsuitable for planting their crops and gain regions with low productivity and low post-harvest storage. Thus, the present study aimed to evaluate the productivity of five garlic cultivars of seminoble group in organic management in the micro-region of the Campo das Vertentes - MG. The experimental design was randomized blocks with five treatments and four replications, using cv. Amarante, Cateto Roxo, Gigante Curitibanos, Gigante do Núcleo e Gigante Roxo. In the plots, each cultivar was arranged in five rows spaced $0.2 \mathrm{~m}$ with plants spaced $0.1 \mathrm{~m}$ within the row, for a total of 50 plants per plot. The five central lines were used for the evaluations forming a Useful plot equal to $1.2 \mathrm{~m}^{2}$. We evaluated the plant height and number of green leaves at sixty, ninety and one hundred and twenty days, total production, mass loss during and after curing and commercial production. Cultivars Gigante do Núcleo, Gigante Curitibanos e Gigante Roxo achieved better performance, with yields above the state average and good commercial classification of bulbs. cleo, Gigante Curitibanos e Gigante Roxo obtiveram melhor desempenho produtivo, apresentando produtividades acima da média estadual e boa classificação comercial de bulbosa.

\section{Palavras-chave}

Allium sativum L

Avaliação regional

Rendimento

\section{Key words}

Allium sativum L

Regional evaluation

Yeld 


\section{1 | Introdução}

A importância econômica da cultura do alho tem aumentado consideravelmente nos últimos anos, sendo cultivado na maioria das regiões brasileiras. É uma hortaliça que se destaca não só pelo seu uso como condimento, mas também por suas propriedades terapêuticas.

O Brasil se destaca como um dos países que mais consomem alho no mundo, apresentando uma demanda anual de, aproximadamente, cento e ciquenta mil toneladas, distribuídas entre 10,0 e 12,0 mil toneladas de consumo mensal, acrescida de 25,0 a 30,0 mil toneladas anuais, utilizadas no plantio da safra seguinte (OLIVEIRA et al. 2003).

Da safra 2006 para a safra 2009, as áreas de cultivo de alho no Brasil mostram características similares, ao redor dos dez mil hectares. Nesse período houve crescimento da produtividade média, de 8,371 toneladas por hectare, em 2006, para 9,075 toneladas, em 2009 (IBGE, 2011). Esse aumento da produtividade é, em grande parte, devido ao clima favorável à cultura e à alta tecnologia que vem ganhando espaço e sendo cada vez mais usada pelos produtores nacionais.

Com a crescente demanda do mercado interno e com o estímulo para o incremento da produção visando à autossuficiência, novas áreas têm sido consideradas potencialmente aptas para a cultura do alho. Como consequência, existe atualmente grande interesse em estudos de competição de clones, no sentido de serem identificados aqueles de melhor adaptação a condições locais específicas (SIQUEIRA et al. 1985).

No mercado brasileiro há uma grande quantidade de clones, com diferentes denominações regionais, acarretando dificuldades na caracterização destes materiais. Por conta disso, muitas das vezes os alicultores adquirem materiais para plantio não adaptado às suas respectivas regiões, e consequentemente obtém colheitas com baixa produtividade e baixa conservação pós-colheita (MOTA, 2005). Apesar de o nosso país possuir condições edafoclimáticas favoráveis à cultura e mão de obra abundante, a alicultura brasileira ainda não é capaz de suprir a demanda do consumo interno de alho, necessitando, ainda, de importações (RESENDE et al. 1999).

As cultivares de alho utilizadas comercialmente no país são divididas em dois grupos, o primeiro agrupa os alhos nobres e o segundo grupo é conhecido como seminobre ou comum. As cultivares seminobre ou comum são adaptadas às condições climáticas da região sudeste do Brasil e apenas o processo de cura feito pelos produtores é suficiente para a quebra da dormência dos bulbilhos, já o material das cultivares nobres a ser plantado nesta região é submetido a um período de vernalização em câmara fria para que tenha uma produção satisfatória (MOTA, 2005).

O cultivo orgânico é baseado em processos biológicos e ecológicos já presentes no ecossistema, pouco ou não polventes, e com o mínimo de aportes externos de natureza não renovável. Busca desenvolver formas de produção que privilegiam a manutenção dos recursos produtivos, tais como solo, água e diversidade genética (FONTES, 2005).

A adubação orgânica é prática bem rotineira entre os alicultores, sendo bem comum os que fazem dela a única fonte de nutrientes para a cultura. Sua aplicação melhora as condições químicas e físicas do solo, nutre as plantas e permite que se processem inúmeras reações vitais, facilitando ainda o aproveitamento dos nutrientes presentes no solo pelas plantas e revertendo esses benefícios em aumento do peso dos bulbos e, consequentemente, aumento de produtividade (MELO; OLIVEIRA, 1999).

Neste contexto, torna-se importante a determinação de cultivares de alho comum com o melhor desempenho na região onde se pretende instalar essa cultura, em função da adaptação do material a ser plantado e do nível tecnológico que será empregado pelo agricultor.

A realização deste estudo com o alho seminobre deu-se em função das baixas temperaturas do inverno na região serem suficientes para atender às exigências deste grupo, e este também se enquadra bem no nível tecnológico disponível aos pequenos produtores de caráter familiar da região. Apesar do custo elevado, as sementes de alho nobre e a vernalização aumentam a produtividade da cultura, mas dificultam seu cultivo por pequenos produtores, responsáveis por uma parte importante da produção brasileira (TRANI et al. 2008). 
Sendo assim, este trabalho teve como objetivo avaliar o desenvolvimento e produtividade de cinco cultivares de alho seminobre em manejo orgânico na microrregião do Campo das Vertentes, região sul de Minas Gerais.

\section{2 | Material e métodos}

O experimento foi realizado no Sítio Roça Grande, localizado no município de Coronel Xavier Chaves/MG, a $21^{\circ} 01^{\prime} 26^{\prime \prime}$ de latitude sul e $44^{\circ} 13^{\prime} 22^{\prime \prime}$ de longitude oeste de Greenwich, com altitude de $930 \mathrm{~m}$, no período de abril a setembro de 2011. O município pertence à microrregião do Campo das Vertentes e fica próximo à cidade de São João Del Rei, MG.

O delineamento experimental usado foi blocos ao acaso, com cinco tratamentos e quatro repetições. Os tratamentos consistiram das cultivares Amarante, Cateto Roxo, Gigante Curitibanos, Gigante do Núcleo e Gigante Roxo. Cada bloco foi composto por canteiros de $5,0 \mathrm{~m}$ de comprimento e 1,2 $\mathrm{m}$ de largura, dividido em cinco parcelas de 1,0 m de comprimento. Nas parcelas, cada cultivar foi disposta em cinco linhas espaçadas de 0,2 m, com plantas espaçadas $0,1 \mathrm{~m}$ dentro da linha, perfazendo um total de 50 plantas por parcela. As cinco linhas centrais foram utilizadas para as avaliações formando uma área útil da parcela igual a 1,2 $\mathrm{m}^{2}$.

As análises químicas e físicas do solo da área onde foi instalado o experimento estão descritas na Tabela 1. Em função dos resultados, foram aplicados corretivos e adubo de origem orgânica, cujos cálculos foram realizados conforme as recomendações da 5 a aproximação (SOUZA et al. 1999). O preparo do solo foi realizado cinquenta dias antes do plantio, com uma aração e uma gradagem. Em seguida, fez-se o preparo dos canteiros com as quantidades recomendadas de calcário para elevar a saturação por base (Ve) a $70 \%$ fosfato natural e $30 \mathrm{t} / \mathrm{ha}$ de esterco bovino curtido. O fosfato e o esterco foram aplicados com trinta dias de antecedência ao plantio. Também foi usada cobertura morta sobre os canteiros. Colocou-se uma camada de palha de feijão com aproximadamente $5 \mathrm{~cm}$ de espessura após o plantio.

Tabela 1: Análises químicas e físicas do solo da área experimental e análise química do adubo orgânico utilizado feitas pelo laboratório do Departamento de Ciência do solo da Universidade Federal de Lavras (UFLA), Lavras,MG, 2011

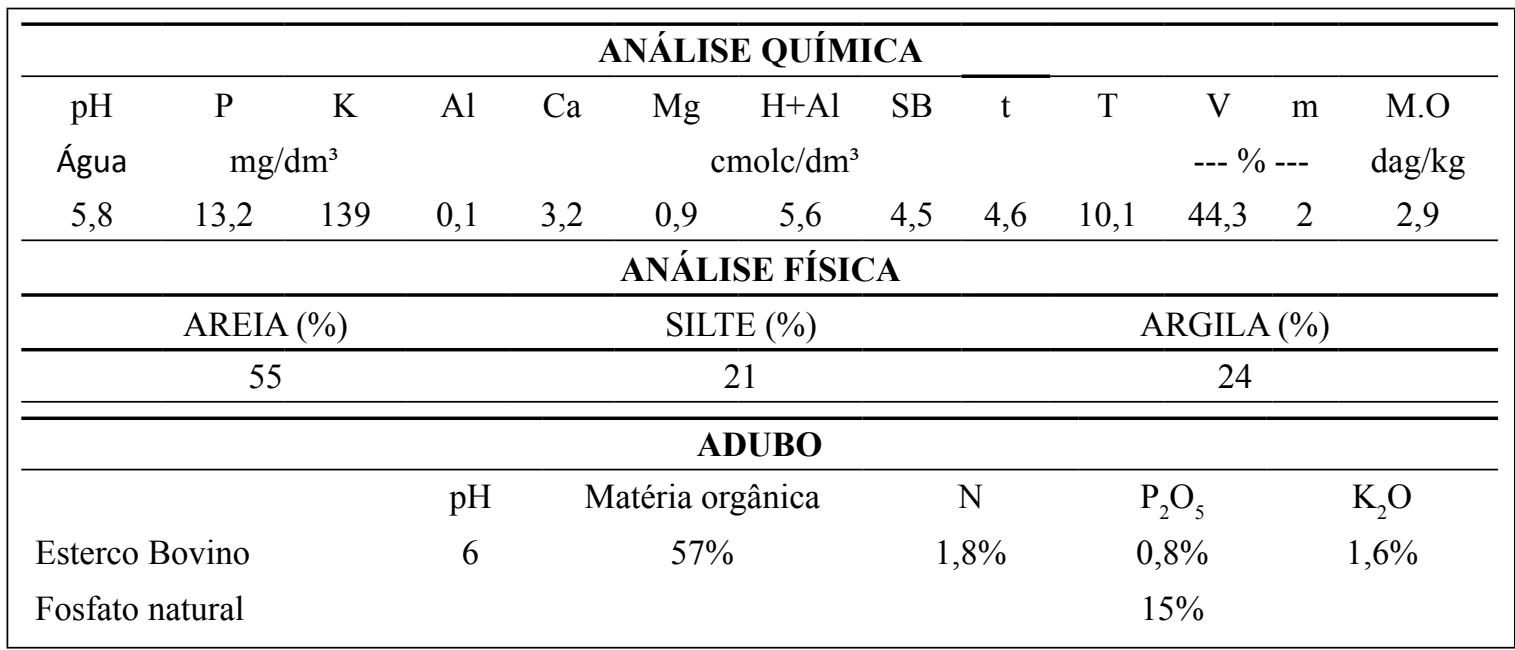

Fonte: Elaboração dos autores.

Na condução do experimento foram utilizadas mangueiras de microaspersão para a irrigação, operação realizada três vezes por semana até o início do quarto mês, quando a irrigação passou a ser feita duas vezes por semana, e completamente suspensa vinte dias antes da colheita.

A cultura do alho está sujeita a uma série de doenças fúngicas, portanto, a prevenção ao ataque destes patógenos no experimento foi feita com pulverizações quinzenais de calda bordalesa e com a seleção rigorosa de bulbilhos sadios para o plantio. Mesmo com todas as medidas preventivas foi constatada a presença de alguns patógenos na lavoura, que não chegaram a causar danos significativos na produção, pois a incidência ocorreu principal- 
mente no final do ciclo da cultura.

Durante o ciclo da cultura, avaliou-se a altura das plantas e número de folhas verdes ativas aos sessenta, noventa e cento e vinte dias após plantio. A medição de altura das plantas foi realizada com uma régua graduada até 100 $\mathrm{cm}$, sendo mensurada a distância do nível do solo até a extremidade da folha mais comprida. Foram medidas dezoito plantas nas três fileiras centrais de cada parcela, sendo seis em cada fileira. Para a quantificação de número de folhas, foram contadas as folhas verdes (fotossinteticamente ativas), sendo contadas nas mesmas dezoito plantas que foram medidas em cada parcela.

Após a colheita, avaliou-se a produção total, perda de massa após a cura ao sol, perda de massa após a cura à sombra e produção comercial das cultivares. A produção total no dia da colheita foi pesada e os valores extrapolados para um hectare, pesando as plantas inteiras logo após a colheita, retirando apenas o excesso de terra e palha da cobertura morta que estavam presos às plantas.

A pré-cura foi feita por cinco dias, as plantas ficaram expostas ao sol em linhas paralelas e próximas umas das outra de modo que as foIhas da linha inferior cobriam os bulbos da linha superior para evitar a insolação direta sobre os bulbos. Após esse período, as plantas inteiras foram novamente pesadas e os valores extrapolados para um hectare.

No processo de cura à sombra, as plantas foram agrupadas em manojos e penduradas com as ramas para cima em local arejado e escuro, onde ficaram por vinte e cinco dias após a pré-cura. Ao final desse período as plantas inteiras foram pe- sadas novamente e os valores extrapolados para um hectare. No mesmo dia foi feita a limpeza dos bulbos ou toalete e a sua classificação comercial.

A classificação comercial foi feita separando e contando a porcentagem de bulbos em cada classe comercial por parcela. Os bulbos foram agrupados de acordo com o tamanho do maior diâmetro nas classes 3, 4, 5, 6, 7 e sem classificação comercial.

Os dados foram submetidos a teste de Hartley $(5 \% \mathrm{P})$, verificando-se não haver evidências de heterogeneidade de variâncias, dispensando o uso de transformações. Os dados das características avaliadas foram submetidas à analise de variância e as médias foram comparadas pelo teste Scott-Knott a 5\% de significância, sendo as análises realizadas no software SISVAR 5.3 Ferreira (2010).

\section{3 | Resultados e discussões}

Para altura de planta até os noventa dias, observou-se diferença significativa entre as cultivares (Tabela 2), sendo que a cultivar Gigante do Núcleo sobressaiu-se, com 58,27 cm aos sessenta dias e 73,09 cm aos noventa dias, enquanto as cultivares Cateto Roxo com $52,71 \mathrm{~cm}$ e Gigante Roxo com 66,37 cm apresentaram menor altura de planta aos sessenta e noventa dias respectivamente. Mota et al. (2005) também constataram menor altura de planta para a cultivar Cateto Roxo aos setenta dias quando comparada a outras cultivares. Já Oliveira et al. (2010) não encontraram diferenças significativas entre a altura das cultivares Amarante, Cateto Roxo, Gigante Roxo e Gigante do Nú-

Tabela 2: Número médio de folhas e altura média em centímetros das plantas de alho aos sessenta, noventa e cento e vinte dias após o plantio.

\begin{tabular}{|c|c|c|c|c|c|c|}
\hline Cultivar & $\begin{array}{c}\text { Altura de } \\
\text { plantas } \\
60 \text { dias }\end{array}$ & $\begin{array}{l}N^{\circ} \text { de } \\
\text { folhas } \\
60 \text { dias }\end{array}$ & $\begin{array}{l}\text { Altura de } \\
\text { plantas } \\
90 \text { dias }\end{array}$ & $\begin{array}{l}\text { No de } \\
\text { folhas } \\
90 \text { dias }\end{array}$ & $\begin{array}{c}\text { Altura de } \\
\text { plantas } \\
120 \text { dias }\end{array}$ & $\begin{array}{c}N^{\circ} \text { de } \\
\text { folhas } \\
120 \text { dias }\end{array}$ \\
\hline Amarante & $53,29 \mathrm{~b}$ & $6,75 a b$ & $67,52 \mathrm{~b}$ & $9,04 a$ & 66,56 a & 9,08 a \\
\hline Cateto Roxo & $52,71 \mathrm{~b}$ & 6,96 a & 69,81 ab & $8,54 a b$ & 68,12 a & 8,62 a \\
\hline Gig. Curitibanos & $56,60 a b$ & $6,04 \mathrm{c}$ & $68,95 a b$ & 8,08 b & $66,19 a$ & 9,92 a \\
\hline Gig. do Núcleo & $58,27 \quad a$ & $6,33 b c$ & $73,09 \quad a$ & $8,17 \mathrm{~b}$ & $70,79 a$ & 9,79 a \\
\hline Gig. Roxo & 54,18 b & $5,83 \mathrm{c}$ & $66,37 \mathrm{~b}$ & $7,87 \mathrm{~b}$ & 65,35 a & 9,33 a \\
\hline CV (\%) & 3,85 & 4,73 & 3,19 & 3,99 & 5,7 & 10,41 \\
\hline
\end{tabular}

Para cada variável, médias seguidas pela mesma letra na coluna não diferem pelo teste Scott-Knott $(p<0,05)$.

Fonte: Elaboração dos autores. 
cleo aos sessenta dias. Provavelmente, estas diferenças ocorrem devido às diferenças edafoclimáticas das regiões onde se plantou cada clone e às diferentes épocas de plantio durante o ano, pois a espécie Allium sativum L., apresenta grande elasticidade fenotípica. Fatores como fotoperíodo, fertilidade do solo, disponibilidade de água, influenciam de forma considerável no desenvolvimento de cada cultivar. A seleção dos maiores bulbilhos para o plantio também pode ter influência nas diferenças desse tipo de característica.

O número médio de folhas aos sessenta e aos noventa dias após o plantio evidenciou diferenças significativas entre as cultivares (Tabela 2). A cultivar Amarante, que tinha 6,75 folhas aos sessenta dias e 9,04 folhas aos noventa dias, juntamente com a cultivar Cateto Roxo, que tinha 6,96 folhas aos sessenta dias e 8,54 folhas aos noventa dias, foram superiores às demais cultivares. Resultado semelhante foi obtido por Mota et al. (2005), que ao avaliar este parâmetro aos setenta dias após o plantio para 6 cultivares de alho comum, observou que a cultivar Amarante, com 8,3 folhas, e a cultivar Cateto Roxo, com 7,26 folhas, foram superiores às demais.
Segundo Shimoya (1970), a planta de alho mantém constante sete a dez folhas, sendo uma em senilidade, cinco a sete adultas e uma a duas em crescimento.

Aos cento e vinte dias após o plantio não houve diferença significativa entre as cultivares nos parâmetros altura de planta e número médio de folhas (Tabela 2), porém as cinco cultivares apresentaram menor altura de planta aos cento e vinte dias que aos noventa dias, provavelmente devido ao estágio fenológico das plantas, no qual estas já estabilizaram o crescimento da parte aérea e estão investindo no acúmulo de reservas.

Pôde-se observar na Tabela 3 que não houve diferença estatística entre as cultivares em relação à produção total de plantas, tanto na colheita quanto após a cura. A cultivar que obteve maior valor para produção total de plantas após a cura foi a Gigante do Núcleo, com 15,73 t/ ha, seguida da cultivar Gigante Curitibanos com 15,35 t/ha. A cultivar Cateto Roxo foi a que obteve menor valor para produção total após a cura, com 12,44 t/ha. Oliveira (1999), comparando produção total de cultivares de alho, também não observou diferença estatística entre as cultivares Gigante Roxo e Gigante Curitibanos.

Tabela 3: Produtividade total de plantas (t/ha) no dia da colheita, após préw-cura, após cura e produção comercial de bulbos em toneladas por hectare.

\begin{tabular}{lcccc}
\hline Cultivar & $\begin{array}{c}\text { Dia da colheita } \\
\text { (t/ha) }\end{array}$ & $\begin{array}{c}\text { Após } \\
\text { pré-cura (t/ha) }\end{array}$ & $\begin{array}{c}\text { Após cura } \\
\text { (t/ha) }\end{array}$ & $\begin{array}{c}\text { Produção } \\
\text { comercial (t/ha) }\end{array}$ \\
\hline Amarante & $23,33 \mathrm{a}$ & $18,44 \mathrm{a}$ & $14,48 \mathrm{a}$ & $12,42 \mathrm{a}$ \\
Cateto Roxo & $17,81 \mathrm{a}$ & $14,69 \mathrm{a}$ & $12,44 \mathrm{a}$ & $11,33 \mathrm{a}$ \\
Gig. Curitibanos & $22,39 \mathrm{a}$ & $19,58 \mathrm{a}$ & $15,35 \mathrm{a}$ & $12,92 \mathrm{a}$ \\
Gig. do Núcleo & $24,69 \mathrm{a}$ & $20,31 \mathrm{a}$ & $15,73 \mathrm{a}$ & $13,67 \mathrm{a}$ \\
Gig. Roxo & $23,54 \mathrm{a}$ & $19,37 \mathrm{a}$ & $15,02 \mathrm{a}$ & $12,73 \mathrm{a}$ \\
\hline CV (\%) & $\mathbf{1 7 , 2 4}$ & $\mathbf{1 3 , 8 1}$ & $\mathbf{1 2 , 6 6}$ & $\mathbf{1 3 , 7 3}$ \\
\hline
\end{tabular}

Para cada variável, médias seguidas pela mesma letra na coluna não diferem pelo teste Scott-Knott $(p<0,05)$.

Fonte: Elaboração dos autores.

As cultivares não se diferenciaram estatisticamente quanto à produção comercial (Tabela 3), e todas as cultivares envolvidas no trabalho apresentam produtividade satisfatória, pois todas apresentaram valores de produtividade próximos ou superiores à produtividade média de Minas Gerais em 2010, que foi de 11,69 t/ha. Apenas a cultivar Cateto Roxo, com 11,33 t/ha, apresentou produtividade menor que a média do Estado na última safra.
Todas as cultivares apresentaram perda de massa de forma semelhante até os trinta dias após a colheita, sendo que a perda de massa foi mais acentuada durante o processo de précura (até o quinto dia após colheita), quando as plantas ficam expostas ao sol (Figura 1). Oliveira et al. (2004) também observaram que no início da fase de conservação pós-colheita de bulbos, geralmente ocorre maior perda de massa, a qual diminui gradualmente com o decorrer do armazenamento. 


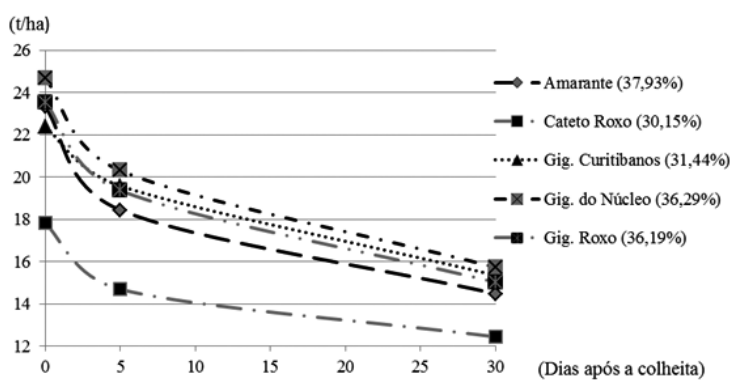

Figura 1: Representação gráfica da perda de massa das cultivares até os 30 dias após a colheita e porcentagem de massa perdida por cada uma delas.

Fonte: Elaboração dos autores.

A perda de massa das cultivares até os trinta dias após a colheita variou entre 30,15\% para cultivar Cateto Roxo e 37,93\% para cultivar Amarante, resultado que se aproxima ao encontrado por Silva et al. (1970), que observou perdas de massa de até $40 \%$ nos primeiros trinta dias após a colheita em plantas de alho, durante $o$ armazenamento em condições ambientais. Oliveira et al. (2010) verificaram diferença na perda de massa entre cultivares de alho após um período de vinte dias de cura e afirma que este resultado demonstra que as cultivares apresentam comportamentos diferentes quanto a perda de água durante o período de cura, e por isso podem necessitar de períodos diferenciados de colheita e cura para alcançarem uma estabilidade de peso para a comercialização.

Quando se compara o tamanho dos bulbos, a diferença observada na produtividade das cultivares é considerável, já que as cultivares com maior peso comercial foram as que obtiveram melhor classificação comercial de bulbos, ou seja, apresentaram maiores bulbos (Figura 2).

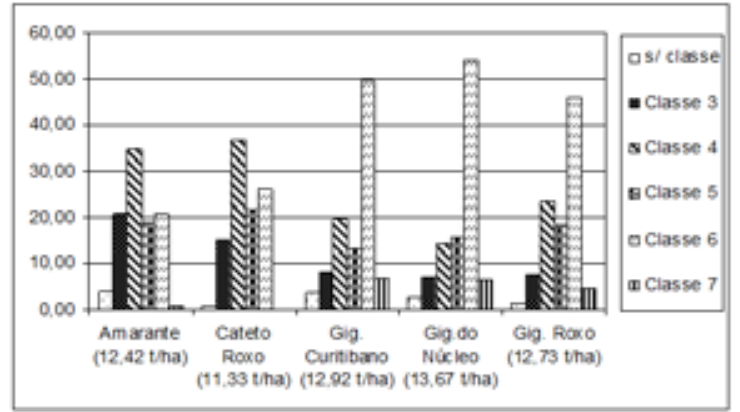

Figura 2: Representação gráfica da porcentagem de bulbos por classe comercial e valores de produtividade para cada cultivar.

Fonte: Elaboração dos autores.
A figura 2 mostra que a cultivar Gigante do Núcleo obteve melhor classificação comercial de bulbos e maior produtividade comercial, 13,67 t/ha. Esta cultivar apresentou $53,83 \%$ dos seus bulbos tamanho 6, a maior porcentagem de bulbos classe 6 dentre as cultivares avaliadas. A cultivar Gigante Curitibanos obteve produtividade de 12,92 t/ha, e a Gigante Roxo obteve $12,73 \mathrm{t} / \mathrm{ha}$, ambas se destacaram quanto à classificação comercial dos bulbos, com 49,50\% e $45,91 \%$ dos bulbos na classe 6 , respectivamente. Tendo em vista que o preço do alho pago ao produtor varia em função da classificação comercial dos bulbos, ter conhecimento desta característica para a cultivar ou cultivares a serem plantadas é importante para que o produtor tenha conhecimento sobre a qualidade dos bulbos que serão colhidos e comercializados (OLIVEIRA, et al. 2010).

As cultivares Amarante e Cateto Roxo obtiveram menor produtividade e a pior classificação comercial, com apenas $20,87 \%$ e $25,92 \%$ de seus bulbos na classe 6 , respectivamente. A maior parte dos bulbos destas duas cultivares foram agrupados na classe 4 , sendo $34,67 \%$ dos bulbos da Amarante e 36,61\% dos bulbos da Cateto Roxo tamanho 4 (Figura 2).

\section{4 | Conclusões}

Considerando-se as variáveis produtivas analisadas, embora não tenha ocorrido diferença estatística, foi observado que as cultivares $\mathrm{Gi}$ gante do Núcleo, Gigante Curitibanos e Gigante Roxo se destacaram quanto à classificação comercial de bulbos, sendo as mais indicadas para o plantio na região.

A microrregião Campo das Vertentes mostrou-se apta para o cultivo orgânico de alho comum, permitindo que se faça um plantio comercial sob manejo orgânico com diversidade de clones, pois quatro das cinco cultivares avaliadas atingiram desempenho produtivo satisfatório, com produtividade acima da média estadual.

\section{Agradecimentos}

À Fundação de Amparo à Pesquisa de Minas Gerais (FAPEMIG) pela concessão de bolsa de estudo e apoio financeiro. 


\section{Referências bibliográficas}

FERREIRA, D. F. SisVar: sistema de análise de variância para dados balanceados, versão 5.3. Lavras: DEX/UFLA, 2010. (Software estatístico)

FONTES, P. C. R. Olericultura: teoria e prática. Viçosa: Suprema, 2005. 486 p. INSTITUTO BRASILEIRO DE GEOGRAFIA E ESTATÍSTICA (IBGE). Sistema IBGE de recuperação automática - SIDRA; Disponível em: <www.sidra.ibge. gov.br/bda/prevsaf/> Acesso em: 21 out. 2011.

MELO, J. P. L. de.; OLIVEIRA, A. P. de. Produção de alho em função de diferentes níveis de água e de esterco bovino no solo. Horticultura Brasileira, Vitória da Conquista, v. 17, n. 1, p. 11-15, mar. 1999. Disponível em: <http://www.scielo.br/scielo.php?pid=S010205361999000100004\&script=sci_arttext > Acesso em: 06 fev. 2012.

MOTA, J. H. et al. Similaridade morfológica de cultivares de alho (Allium sativum L.). Revista Científica Eletrônica de Agronomia, Garça, v. 08. dez. 2005. Disponível em: < http://www. revista.inf.br/agroo8/artigos/artigo02.pdf> Acesso: 10 out. 2011.

OLIVEIRA F. L. et al. Características agronômicas de cultivares de alho em Diamantina. Horticultura Brasileira, Brasília, v. 28, n. 3, p. 355-359. jul.-set. 2010. Disponível em: <http:// www.revista.inf.br/agroo8/artigos/artigo02.pdf > Acesso em: 10 out. 2011.

OLIVEIRA, C. M. Determinação do ponto de colheita em cultivares de alho. Lavras: UFLA, 1999. 51p.

OLIVEIRA, C. M. et al. Determinação do ponto de colheita na produção de alho. Horticultura Brasileira, Brasília, v. 21, n. 3, p. 506-509, jul.set. 2003. Disponível em: <http://www.scielo. $\mathrm{br} / \mathrm{pdf} / \mathrm{hb} / \mathrm{v} 21 \mathrm{n} 3 / 17591 . \mathrm{pdf}>$ Acesso em: 10 out. 2011.

OLIVEIRA, C. M. et al. Época de colheita e potencial de armazenamento em cultivares de alho. Horticultura Brasileira, Brasília, v. 22, n. 4, p. 804-807, out.-dez. 2004.
RESENDE, F. V. et al. Acúmulo de matéria seca e exigências nutricionais de plantas de alho provenientes de cultura de tecidos e de propagação convencional. Horticultura Brasileira, Brasília, v. 17 n. 3, p. 220-226, nov. 1999.

RIBEIRO, L. F.; BEDENDO, I. P. Efeito inibitório de extratos vegetais sobre Colletotrichum gloeosporioides - agente causal da podridão de frutos de mamoeiro. Scientia Agricola, v. 56, n. 4, 1267-1271, 1999. Disponível em: $<$ http://www.scielo.br/scielo.php?pid=S010390161999000500031\&script=sci_arttext $>$ Acesso em: 10 out. 2011.

SHIMOYA, C. Anatomia do bulbo do alho (Allium sativum L.) durante seu ciclo vegetativo. Revista Ceres, Viçosa, v. 17, n. 91, p. 1021018, jan.-mar. 1970.

SILVA, N. D. A. et al. Nutrição Mineral de Hortaliças. XI. Absorção de Nutrientes pela Cultura do Alho. O solo, Piracicaba, v. 62, n. 1, p. 7-17, 1970.

SIQUEIRA, W. J. et al. Caracterização isoenzimática e morfológica de clones e introduções de alho. Bragantia, Campinas, SP, v. 44, n. 11, p. 357-374, 1985 .

SOUZA, R. J. de, PAULA M. B. de; CECÍLIO FILHO, A. B. Sugestão de adubação para hortaliças "Alho" In: RIBEIRO, A. C. et al. (Ed.). Recomendação para o uso de corretivos $e$ fertilizantes em Minas Gerais: 5. Aproximação. Viçosa: Comissão de Fertilidade do Solo do Estado de Minas Gerais, 1999. p. 25-32.

TRANI, P. E. et al.F. A. Produtividade de cultivares de alho na região paulista de Tietê. Bragantia, Campinas, SP, v. 67, n. 3, p. 713-716, 2008. 


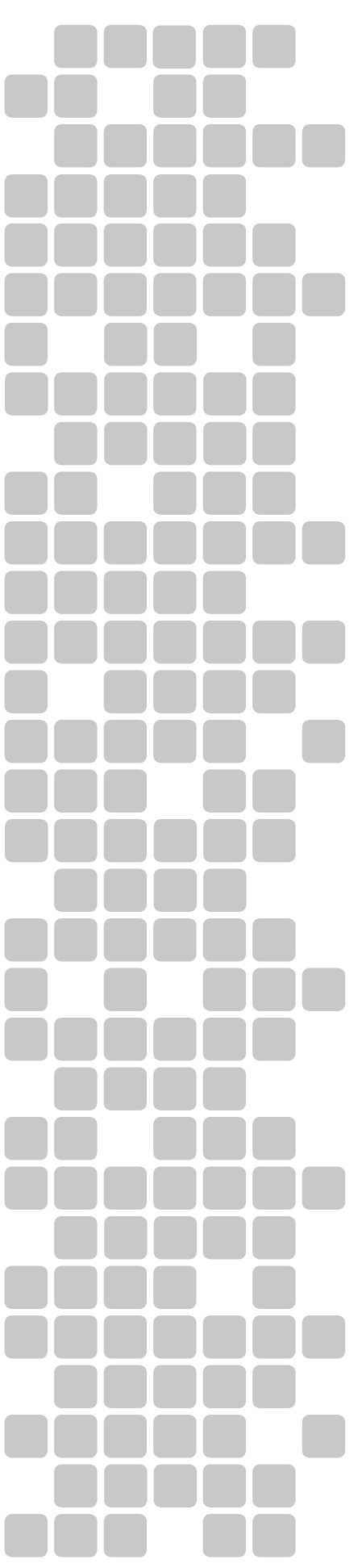

1 Mestrando em Bioengenharia do Departamento de Engenharia de Biossistemas da Universidade Federal de São João Del Rei, Campus CSA/UFSJ, CEP. 36307-352, brenoterra@hotmail.com

2 Doutorando em Fitotecnia do Departamento de Agricultura da Universidade Federal de Lavras, Lavras, Minas Gerais, Campus Universitário UFLA, Caixa postal 3037, cep. 37200-000, julioagro@gmail.com

3 Professor Adjunto do Departamento de Agricultura da Universidade Federal de Lavras, Lavras, Minas Gerais, Campus Universitário UFLA, Caixa postal 3037, cep. 37200-000, rovilson@dag.ufla.br 